\title{
Developing a Sealant Program: the Massachusetts Approach*
}

\author{
Virginia A. Callanen, MS, MPH \\ Project Director \\ Division of Dental Health \\ Massachusetts Department of Public Health \\ 150 Tremont Street \\ Boston, MA 02111
}

\author{
Jane A. Weintraub, DDS, MPH \\ Assistant Professor \\ Program in Dental Public Health \\ School of Public Health \\ The University of Michigan \\ Ann Arbor, MI 48109-2029
}

Donna P. French, RDH, MS

Assistant Project Director

\author{
Gregory N. Connolly, DMD, MPH \\ Director \\ Division of Dental Health \\ Massachusetts Department of Public Health
}

Abstract

This paper describes the program structure and strategies being used by the Massachusetts Department of Public Health to promote the utilization of sealants. The program design includes four components: clinical demonstration, consumer education, professional education, and reimbursement. Eighteen Massachusetts neighborhood health centers and six local health departments are participating in the clinical demonstration component. Since March 1984, dental personnel from these sites have applied sealants to 4,398 schoolchildren. The promotional theme "Save Teeth: Seal Them" has been incorporated into brochures designed to increase knowledge and awareness of consumers. Curriculum materials have been developed to educate dentists and dental hygienists to apply sealants and understand the rationale and scientific basis for their use. Since January 1984, 18 sealant educational sessions have been conducted statewide for 630 dental providers. Information is being presented to third-party carriers, some of whom have subsequently adopted a policy to include reimbursement for sealants.

Key Words: pit-and-fissure sealants, caries-prevention methods, public health programs, organization and administration, promotion

\section{Introduction}

The Massachusetts Department of Public Health's (MDPH) Division of Dental Health conducted a survey of the dental health of 9,000 Massachusetts schoolchil-

Address correspondence to and request reprints from Ms. Callanen.

*This project is funded by DHHS Grant MCJ 253328. dren from 1979-81 (1). The survey found that by age 17 the average Massachusetts adolescent has had 14 tooth surfaces affected by decay, 30 percent higher than the national average.

The primary goal of the MDPH's Division of Dental Health is to prevent and control dental disease. Currently, 55 percent of Massachusetts residents receive the benefits of community water fluoridation and promotional efforts are being continued to extend this benefit to all residents. Additionally, 100,000 children from 166 cities and towns participate in school-based fluoride mouthrinsing programs.

Although the use of topical and systematic fluorides does provide some protection to the occlusal surfaces, the smooth surfaces generally derive greater benefit from fluorides (2). The National Dental Caries Prevalence Survey of 1979-80 found that 54 percent of all decayed, missing, and filled surfaces in 5-17-year-old children involved occlusal surfaces ( 84 percent if buccal and lingual surfaces are included) (3). Properly applied pit-and-fissure sealants can effectively prevent dental caries on occlusal surfaces and buccal and lingual pits and fissures. Used in conjunction with fluorides, sealants provide optimum caries protection (4). Yet despite their effectiveness and ease in application, sealants have been adopted slowly by the dental profession (5).

Recognizing that the low or infrequent use of sealants is a public health issue that should be addressed, the Division of Dental Health in the spring of 1983 designed a program to increase sealant use in Massachusetts. The primary goal of the program is to reduce the incidence of dental caries in Massachusetts children through increased use of dental sealants. Funds to implement this program were requested from the United States Department of Health and Human Services (DHHS), Division of Maternal and Child Health 
through the Massachusetts Health Research Institute, Inc. (MHRI). MHRI is a private, nonprofit organization founded to assist private and public agencies engaged in carrying out research, demonstration, and training projects. Funds for this three-year program were appropriated by DHHS in October 1983 from the federal Special Projects of Regional and National Significance (SPRANS).

\section{Methods}

To achieve the goal of widespread sealant use in Massachusetts, the MDPH Division of Dental Health is striving to increase sealant knowledge and awareness by the consumer, the provider, and the policy maker through a four-component program.

1. Demonstration Component-initiates sealant demonstration programs into ongoing preventive dental activities of health centers, local health departments, and schools.

2. Consumer Education Component-develops and distributes sealant educational and promotional materials to consumers.

3. Professional Education Component-increases the number of dental personnel who will respond to consumer demand for scalants by teaching new skills and current knowledge about sealants.

4. Reimbursement Componont-removes financial barriers by developing third-party coverage for sealants.

A description of this four-part program follows in the next sections.

Demonstration Component. Site Selection. Phase One of the clinical demonstration component began in January 1984 in the city of Boston. Boston was chosen as the initial site because of its extensive network of neighborhood health centers with dental programs located in areas of economic need. Boston has also been fluoridated since 1978.

Phase Two, expansion to other parts of the state, began in October 1984. Prior to program expansion in fall 1984, all local health departments in Massachusetts were surveyed to determine available dental staff, equipment, types of preventive services offered in schools, and interest in participating in the sealant program.

The Division of Dental Health in conjunction with MHRI issued a request for proposals to potential vendors, including neighborhood health centers and local health departments, to incorporate the sealant program into ongoing preventive dental activities for schoolchildren.

An MDPH review committee examined the submitted proposals and made selections of health centers and health departments based upon:

(1) access to the target population of children aged 514 ;

(2) geographic location of the health center or health department (low socioeconomic areas receive priority);

(3) existence of community water fluoridation or fluoride mouthrinsing programs or both (preferred, but not required);
(4) availability of dental hygienists to apply sealants under the general supervision of a dentist as allowed by the Massachusetts State Dental Practice Act and dentists to screen children;

(5) administrative support from local schools; and

(6) willingness of dental hygienists and dentists to attend a one-day sealant educational session.

Contractual Agreements. A contractual agreement was entered into between the Massachusetts Health Research Institute, Inc., and each selected health center or local health department. The contract specified the obligations of the local health center or local health department, including:

(1) the application of sealants to the teeth of eligible children as recommended by the MDPH in its sealant application manual;

(2) use of the best efforts to inform parents, children, and teachers about the program and to encourage participation;

(3) maintenance of records and submission of monthly reports to MDPH;

(4) periodic site visits of facilities to observe sealant application and program operations by the Division of Dental Health sealant project staff; and

(5) the provision of supplies and use of MDPH portable equipment.

Monthly invoices are submitted to MHRI by each contract site. Rates of reimbursement are derived from the budgets submitted by health departments and health centers during the request for proposal process and a mean cost per sealed tooth is determined for each site.

Program Operation. Two types of programs are operating: a health center-based program and a school-based program. In the health center program, sealants are applied to the teeth of children between the ages of 5-14 who meet the MDPH criteria for sealants and who are receiving regularly scheduled dental preventive and treatment services. The MDPH has been recommending that the occlusal surfaces of recently erupted permanent molars be sealed if they are sound, unrestored, and can be kept dry and free of gingival contact. Providers are particularly encouraged to seal molars that have deep, narrow pits that easily catch the tine of an explorer. In situations where it is difficult to determine whether or not a pit is sound or decayed, the judgment of whether or not to seal the pit is determined be the screening dentist. The MDPH, however, encourages the providers to seal teeth in these questionable circumstances. Children with rampant caries or many proximal lesions, however, are not considered good candidates for sealants.

All participating children are placed on a recall schedule and reexamined six months to a year after sealant placement. Sealants are replaced if necessary.

In the school-based program, local health departments and neighborhood health centers incorporate the use of sealants into their ongoing caries prevention programs for first-, second-, and sixth-grade schoolchildren. Caries prevention programs are designed at the local level and may include one or more of the following: fluoride mouthrinses, topical applications of 
fluoride, prophylaxes, dental health education, and sealants. Sealant application sessions are conducted nearby at the neighborhood health center or health department dental clinic or in the school setting using portable dental equipment.

Many of the Massachusetts neighborhood health centers and local health departments have transportation programs in place for provision of dental preventive and treatment services of school-aged children. Students leave the classroom for short periods of time to receive these services. Some children walk to the dental clinic if it is close to the school or are transported by bus or taxi. Several of the selected contractors have chosen to incorporate sealants into these programs.

In addition, through the Maternal and Child Health Grant, three sets of portable dental equipment have been purchased for use in schools. Each set of portable dental equipment includes a dental chair, dental unit with high- and low-volume suction, compressor, operator and assistant stools, autoclave, extraoral light, visible curing light, protective eyeglasses, dental instruments, nondisposable supplies, and sealant. Either chemical or visible light-cured sealant is supplied depending on the provider's preference. The health center or local health department may borrow the equipment for a designated period of time to use in the school-based program upon agreement to secure, maintain properly, and return all loaned materials.

Transportation of the portable dental equipment is a cooperative effort between the MDPH sealant project staff and each contract site. The project staff members transport the equipment to the initial school site in each area. Moring the equipment to successive school sites in the community is the responsibility of the contracted health department or health center.

To optimize the number of erupted first and second molars available for sealing, it is preferable to see firstand sixth-grade children late in the spring of the school year and second-grade children in the fall.

Each health center or health department is responsible for the selection of local schools and subsequent program implementation. This includes selecting community schools that exhibit need, obtaining approval from school administrators, and making arrangements with school staff. The health center or health department provides a dental team consisting of a dentist to conduct the screenings, a recorder to enter the findings, a dental hygienist to apply the sealants, and, if available, a dental assistant. The team also is responsible for distributing promotional materials; receiving signed, informed consent forms and pertinent health histories from parents of children who are to participate; maintaining records; and submitting monthly progress reports. Parents of participating children are given a written record of their child's dental health status and service performed. If obvious dental disease is present, parents are notified by letter that their child should see a dentist soon.

Monitoring. Monitoring of the health center and school-based programs is accomplished through the submission of monthly reports, on-site visits, and frequent telephone contact.
Data are collected continuously of the number o children with permission to participate, number of chil dren examined, number of children indicated for seal ants, number of children treated, number of teetr sealed, number of teeth sealed per child treated, anc the number of teeth resealed. A dental examinatior form is completed for each child during the initia screening and during successive examinations in orde: to monitor the status of the occlusal surfaces. It was not, however, the intent of this project to replicate the research that demonstrated the effectiveness or efficacy of sealants. Consequently, screening dentists were no calibrated. If contract site personnel encounter difficul. ty with the logistics and implementation of the school based program, project staff are readily available for consultation and guidance either by telephone on through on-site visits.

Consumer Education Component. A critical component of the program is promoting public awareness anc knowledge concerning the effectiveness of sealants The demonstration program just described is the prin cipal vehicle for achieving this goal. It was anticipated that participating children would tell their friends and siblings about sealants, that their parents would tel friends and neighbors, and that participating schoo personnel would tell colleagues in other schools.

\section{A critical component of the program is promoting public awareness and knowledge concerning the effective- ness of sealants.}

The theme "Save Teeth: Seal Them" and "friendly seal" logo were developed to enhance our promotional activities. Three brochures based on this theme were produced, including a coloring book entitled Sealants for Molly and Michael Molar, A Parents' Guide to Dental Sealants, and a Dental Health Fact Sheet on Sealants. The parents' guide was distributed with parental consent forms and the coloring books and seal logo stickers were given to participating children. The fact sheet was used by parents, teachers, school administrators, and health professionals. The brochures are suitable for use by private dental practitioners, as well.

Professional Education Component. Pit-and-Fissure Sealants: a Reference and Training Manual (5) has been developed for dental and dental hygiene students, public and private dentists, and dental hygienists who are without previous knowledge of sealants. The manual includes detailed information about sealant application technics and the rationale and scientific basis of sealant use. Application of sealants by a hygienist, rather than a dentist, is the less costly method of providing this service. Educating both hygienists and dentists, however, is emphasized in the Massachusetts program, since dentists are encouraged to delegate the procedure to their hygienists.

The sealant educational programs for private practitioners include a two-hour didactic session, a half-hour 
TABLE 1

Massachusetts Department of Public Health's Dental Sealant Program: Summary Statistics of Demonstration Component in Health Centers and Schools for Phases One and Two Combined, 1984-85

\begin{tabular}{|c|c|c|c|c|}
\hline & $\begin{array}{l}\text { Health } \\
\text { Center }\end{array}$ & School & School & Totals \\
\hline Number of months of program operation & 19 & 12 & 8 & \\
\hline Age of participating children & $5-14$ & Grades 1, 2 & Grade 6 & \\
\hline Number of children examined & 5,935 & 3,187 & 607 & 9,729 \\
\hline Percent eligible children & 57 & 67 & 68 & \\
\hline Number of recipients & 2,871 & 1,717 & 264 & 4,852 \\
\hline Number of teeth sealed & 8,391 & 5,169 & 958 & 14,518 \\
\hline Mean number of teeth sealed/child & 2.92 & 3.01 & 3.63 & 2.99 \\
\hline
\end{tabular}

preclinical session, and a two-hour supervised clinical session. Classroom and clinical space are used at schools of dental hygiene and dental medicine; instruction and supervision are provided by Massachusetts Division of Dental Health personnel. Special sessions conducted for participating dental personnel from health center and health department contract sites include the goals and objectives of the grant, operation of school-based programs, and use of portable dental equipment.

Reimbursement Component. In the fall of 1983, an informational package entitled Dental Sealants: Information and Guidelines for Dental lnsurance Carriers was developed and submitted to Dental Service Corporation of Massachusetts (the largest dental insurance carrier in the state), the Massachusetts Rate Setting Commission, and the Department of Public Welfare. The contents of the informational package included:

(1) recommendations for dental insurance carriers for including sealants as a benefit,

(2) annotated references that address concerns about sealants.

(3) determining the cost of placing a sealant, and

(4) selected readings.

The Division of Dental Health has been available to these groups to answer policy-related questions concerning sealants.

\section{Results and Discussion}

Demonstration Component. Table 1 summarizes the combined results from Phase One and Phase Two of the sealant demonstration component during a 19month period.

In Phase One, 13 of the 22 Boston neighborhood health centers with dental programs applied for and received funds to participate in the health center-based program. In addition, seven of these health centers were awarded funds to establish 14 school-based programs. Children in four of the school programs received sealant applications at school sites, and the children in the remaining 10 schools were transported to health centers.

Phase Two included expansion to other parts of the state. Of the 125 health departments responding to the survey of local health departments, 76 reported dental health activities in schools and 47 of them employed a dental hygienist. Of the health departments (some with and some without dental hygienists), 47 were interested in incorporating sealants into their preventive dental activities and 18 expressed their intent to apply for funds. In October 1984, proposals were reviewed and six local health departments and five health centers were selected in addition to the 13 health centers from Phase One, a total of 18 health centers. Twenty-five neighborhood health centers in Massachusetts have dental programs.

These contracted sites have established 18 health center-based programs and 41 school-based programs in Phase Two. Portable dental equipment is used in 12 schools and children from the remaining 29 schools are transported to health department or health center dental operatories. Sixth-grade children were added to the school-based component in Phase Two.

The percentage of children with permission to participate declined from 68 percent to 50 percent as the program expanded to include local health departments in regions outside Boston. In the city of Boston, health centers participating in school-based programs generally function within the confines of small geographic neighborhoods inhabited by families in economic need. Sometimes the health center is physically located within the school, which may facilitate the return of permission slips. The health center-based contract site may also be more aggressive in receiving signed consent forms because the sealant program is a source of revenue to the health center. The sealant program may not be as important as a revenue source to local health departments that operate programs in many schools scattered throughout an entire town.

The percent eligibility is higher for children participating in the school-based program compared to the health center-based program. Children who go to a health center may be self-selected if they are experiencing pain or obvious decay factors, which could contribute to their lower rates of eligibility. Children screened in the schools are usually without complaints and may be more likely candidates for sealants.

A steady flow of patients is maintained by allowing two children to leave the classroom, so that one child can observe while the other child receives the sealant application. This observation by the next patient also 
TABLE 2

Massachusetts Department of Public Health's Dental Sealant Program: Reimbursement for Health Center and School-based Programs Phases One and Two, 1984-85

\begin{tabular}{lccccc}
\hline & \multicolumn{2}{c}{ Health Center } & & \multicolumn{2}{c}{ School-based } \\
\cline { 2 - 3 } \cline { 5 - 6 } & Phase One & Phase Two & & Phase One & Phase Two \\
\hline Mean number of teeth sealed/child & 2.81 & 3.00 & & 3.13 & 3.09 \\
Reimbursement/tooth & 6.00 & 6.00 & & 7.00 & 4.00 \\
Mean reimbursement/child treated & 16.86 & 18.00 & & 21.90 & 12.39 \\
\hline
\end{tabular}

helps to prepare the child psychologically for the procedure. The child whose sealant application is completed returns to the classroom and sends a third child. This process continues throughout the school day.

One dental hygienist working with the aid of an assistant can apply sealants to 12 children during one school day of six hours. This number has been consistent across contract sites.

Equipment breakdown has interfered with this level of productivity on several occasions. Sealant applications are curtailed until the repair is completed. Frequently moving the equipment in the back of an automobile plus its use by many operators may contribute to the need for repairs. On separate occasions in Phase Two, contract sites have experienced difficulties with the extraoral light, unit, and compressor. Contract sites incorporating sealants into their ongoing transportation programs for schoolchildren have not experienced delays because of portable equipment repairs. This method usually removes the child from the classroom for a longer time period, however.

Table 2 summarizes the rates of reimbursement for health center and school-based programs during Phases One and Two.

Contracts with Boston neighborhood health centers specified a uniform rate of reimbursement in Phases One and Two: $\$ 6.00$ per tooth for sealants applied in the health center program and $\$ 7.00$ per tooth for sealants applied in the school-based program. These rates of reimbursement were derived from the budgets submitted to MHRI during the request for proposal process. Health center administrators were asked to include in their applications the direct costs of dental personnel and supplies, but not the costs of training of personnel, equipment, or indirect costs. Using the submitted costs, a uniform rate was determined based upon the mean salaries of Boston health center dental hygienists and dental assistants, an estimated chairtime of $30 \mathrm{~min}$ uted per child, and an estimated cost of supplies per child. The rate for teeth sealed in the health center conducted school-based programs included the additional cost for a dentist to conduct screenings.

In Phase Two, with the addition of contracts with local health departments, reimbursements for teeth sealed in the school program varied from $\$ 2.00$ to $\$ 7.00$ per tooth. This variation is due to the amount of donated contribution from local health departments. Correspondingly, the mean reimbursement per child participating in the school program declined in Phase Two. Local health departments were requested to submit a budget for items that would be required by the health department to conduct the sealant program. These items included the cost of supplies, hourly reimbursement for a dental hygienist with the aid of a dental assistant to apply sealants, and for a dentist and a recorder to conduct screenings. Since the majority of these health departments employed a full-time dental hygienist, reimbursement requests were generally limited to the cost of supplies and hourly salaries for a dentist and recorder team to conduct screenings. The rates of reimbursement do not include capital equipment, since portable dental equipment was available on a loan basis to health departments and health centers participating in the school program.

Consumer Education Component. The brochures developed in Phase One to educate consumers have been distributed at no charge to all health centers, local health departments, and schools participating in the demonstration component. The contract sites have distributed 24,000 brochures.

Health centers and health departments have issued local and regional press releases with the initiation of the demonstration program in each community and items have appeared in 18 Massachusetts newspapers. Health centers and health departments also have worked with local radio stations and regional health fairs to inform their communities of the availability of the sealant program.

Announcements regarding the availability of the sealant brochures have appeared in the newsletters of the Centers for Disease Control, Massachusetts Dental Service Corporation, and the American Dental Hygienists' Association. As a result, 26,000 brochures have been disseminated to requesting dental providers from other states for the cost of reprinting. The August 1985 issue of the American Dental Hygienists' Association's HORIZONS, which described the brochures, prompted requests from 175 dental providers in 40 states in less than two weeks.

Professional Education Component. Since January 1984, 18 educational sessions have been conducted for 630 dental hygienists, dentists, dental hygiene school faculty members, dental students, and public health professionals.

Project staff have conducted sealant classes for dental students attending preventive dental courses in the three dental schools in Massachusetts. Presentations also have been given to faculty members of five schools of dental hygiene in the state. Providing classes for students and faculty has stimulated the incorporation 
of the scientific rationale for sealants and their clinical application into dental and dental hygiene school curricula in Massachusetts.

The response to professional educational opportunities has been favorable. In June 1984, MDPH cosponsored two continuing education courses with Dental Service Corporation of Massachusetts. Over 400 (11 percent) Dental Service Corporation providers asked to attend the courses. Unfortunately, only 100 providers could be accommodated because of limited clinical space. In response to this demand for continuing education and a new Dental Service Corporation policy to include sealants as a covered benefit, a cooperative educational program was initiated with the Dental Service Corporation in Phase Two. Seven sealant educational sessions have been conducted for these dental providers in varying parts of Massachusetts.

Sealant education has also beer conducted on a regional basis, including the annual Yankee Dental Congress sponsored by the dental s.xcieties of the New England states and the annual meeting of the New England Headstart Dental Consultants.

Reimbursement Component. The Division of Dental Health staff met with administrators of the Massachusetts Dental Service Corporation (DSC) and the Department of Public Welfare, which administers the Medicaid Program, on several occasions following the distribution of Dental Sealants: Information and Guidelines for Dental Insurance Carriers in the fall of 1983. In January 1984, the board of the DSC voted to include sealants as a covered benefit and administration of benefits for pitand-fissure sealants began October 1, 1984. Current enrollment in the DSC plans is approximately 500,000 persons, or 10 percent of the state's population.

In addition, recommended revisions for the Dental Medicaid Program were submitted by MDPH to the Department of Public Welfare. There are approximately 60,000 Medicaid-eligible children in the age category 614 residing in Massachusetts.

\section{Conclusions}

The MDPH Division of Dental Health has designed and implemented a program to increase sealant use in Massachusetts. The MDPH judges that its methods do increase sealant knowledge and awareness by the consumer, the provider, and the policy maker and may be used to promote sealant adoption in other states.

\section{References}

1. DePaola PF, Soparker M, Tavares M, Allukian M, Peterson H. A dental survey of Massachusetts schoolchildren. I Dent Res 1982;61(Sp. Iss.): $1356-60$.

2. Horowitz HS. The potential of fluorides and sealants to deal with problems of dental decay. Pediatric Dentistry 1982;4:286-95.

3. Miller AJ, Brunelle JA, Carlos JP. The prevalence of dental caries in United States children 1979-1980. The National Dental Caries Prevalence Survey. Bethesda, MD: National Caries Program. National Institute of Dental Research, NIH Publication No. 82-2245, December 1981.

4. Koop CE. Dental sealants. J Public Health Dent 1984 Summer; $44: 126$.

5. Horowitz AM, Frazier PJ. Issues in the widespread adoption of pit and fissure sealants. J Public Health Dent 1982 Fall;42:312-23.

6. Callanen V, French DP, Weintraub J. Pit and fissure sealants. Reference and training manual. Boston MA: Division of Dental Health, Massachusetts Department of Public Health, 1984.

\section{ANNOUNCEMENT}

Preventing Pit and Fissure Caries: A Guide to Sealant Use has just been published by the Massachusetts Department of Public Health, Division of Dental Health, in collaboration with the Massachusetts Health Research Institute, Inc.

Preventing Pit and Fissure Caries: A Guide to Sealant Use provides dentists, dental auxiliaries and public health professionals with guidelines for sealant use in individual office settings and community preventive dentistry programs.

The guide was prepared by Louis W. Ripa, Harry M. Bohannan, Virginia A. Callanen, Gregory N. Connolly, Judith A. Disney, James R. Hardison, Alice M. Horowitz, and Richard J. Simonsen. The recommendations presented are based on an evaluation of consensus opinion developed by the committee.

Preventing Pit and Fissure Caries: A Guide to Sealant Use is available for $\$ 6.50$ per copy. Make check payable to: CQ-MHRI sealant Guide. Mail check and order to: CQ-MHRI Sealant Guide, PO Box 277, Everett, MA 621.19. 